Article

\title{
Polymer of Intrinsic Microporosity (PIM-1) Membranes Treated with Supercritical $\mathrm{CO}_{2}$
}

\author{
Colin A. Scholes ${ }^{1, *}$ and Shinji Kanehashi ${ }^{2}$ \\ 1 Department of Chemical Engineering, the University of Melbourne, VIC 3010, Australia \\ 2 Graduate School of Engineering, Tokyo University of Agriculture and Technology, Tokyo 184-8588, Japan; \\ kanehasi@cc.tuat.ac.jp \\ * Correspondence: cascho@unimelb.edu.au; Tel.: +61-3-9035-8289
}

Received: 19 December 2018; Accepted: 11 March 2019; Published: 18 March 2019

check for updates

\begin{abstract}
Polymers of intrinsic microporosity (PIMs) are a promising membrane material for gas separation, because of their high free volume and micro-cavity size distribution. This is countered by PIMs-based membranes being highly susceptible to physical aging, which dramatically reduces their permselectivity over extended periods of time. Supercritical carbon dioxide is known to plasticize and partially solubilise polymers, altering the underlying membrane morphology, and hence impacting the gas separation properties. This investigation reports on the change in PIM-1 membranes after being exposed to supercritical $\mathrm{CO}_{2}$ for two- and eight-hour intervals, followed by two depressurization protocols, a rapid depressurization and a slow depressurization. The exposure times enables the impact contact time with supercritical $\mathrm{CO}_{2}$ has on the membrane morphology to be investigated, as well as the subsequent depressurization event. The density of the post supercritical $\mathrm{CO}_{2}$ exposed membranes, irrespective of exposure time and depressurization, were greater than the untreated membrane. This indicated that supercritical $\mathrm{CO}_{2}$ had solubilised the polymer chain, enabling PIM-1 to rearrange and contract the free volume micro-cavities present. As a consequence, the permeabilities of $\mathrm{He}, \mathrm{CH}_{4}, \mathrm{O}_{2}$ and $\mathrm{CO}_{2}$ were all reduced for the supercritical $\mathrm{CO}_{2}$-treated membranes compared to the original membrane, while $\mathrm{N}_{2}$ permeability remained unchanged. Importantly, the physical aging properties of the supercritical $\mathrm{CO}_{2}$-treated membranes altered, with only minor reductions in $\mathrm{N}_{2}, \mathrm{CH}_{4}$ and $\mathrm{O}_{2}$ permeabilities observed over extended periods of time. In contrast, $\mathrm{He}$ and $\mathrm{CO}_{2}$ permeabilities experienced similar physical aging in the supercritical treated membranes to that of the original membrane. This was interpreted as the supercritical $\mathrm{CO}_{2}$ treatment enabling micro-cavity contraction to favour the smaller $\mathrm{CO}_{2}$ molecule, due to size exclusion of the larger $\mathrm{N}_{2}, \mathrm{CH}_{4}$ and $\mathrm{O}_{2}$ molecules. Therefore, physical aging of the treated membranes only had minor impact on $\mathrm{N}_{2}, \mathrm{CH}_{4}$ and $\mathrm{O}_{2}$ permeability; while the smaller $\mathrm{He}$ and $\mathrm{CO}_{2}$ gases experience greater permeability loss. This result implies that supercritical $\mathrm{CO}_{2}$ exposure has potential to limit physical aging performance loss in PIM-1 based membranes for $\mathrm{O}_{2} / \mathrm{N}_{2}$ separation.
\end{abstract}

Keywords: polymer of intrinsic microporosity; supercritical carbon dioxide; aging; permeability

\section{Introduction}

Polymers of intrinsic microporosity (PIMs) are attractive for polymeric membranes, because of their very high fractional free volume and favourable interconnectivity between micro-cavities [1,2]. For many gas pairs, PIMs-based membranes are on or above the Robeson's upper bound, the criterion denoting current state-of-art performance in gas separation membranes [3]. This high performance is the result of the spirobisindane moiety, creating rigid ladder-type polymeric chain structures, with significant steric hindrance preventing chain rotation and limiting chain packing. However, PIMs-based polymeric membranes suffer from a reduction in separation performance over time, known 
as physical aging [4]. This is evident by an initial rapid decline in gas permeability on the order of days, which tampers off to a gradual decline over extended time periods [5]. This physical aging phenomenon in PIMs is similar to behaviour reported for other very high fractional free volume polymers, such as poly [1-(trimethylsilyl)-1-propyne] (PTMSP) [6,7], and established by Swaidan et al. [8] as being due to a collapse in the larger micro-cavity elements within the morphology, creating a denser structure. This occurs because PIMs, being glassy polymers, are in a non-equilibrium state and hence, over time, slow polymer chain relaxation and motion alter the membrane's morphology.

Several studies have investigated solutions to counter or reverse physical aging in PIMs-based membranes. The most common approach is a methanol wash, which removes residual casting solvent and permits the relaxation of polymer chains, leading to an increase in fractional free volume once the methanol is evaporated [9]. Similarly, chemically modifying or cross-linking PIMs-based membranes alter the permselectivity of the membrane and limit age-induced changes to the membrane's performance [10-12]. Another approach has been to incorporate particles into the PIMs structure to form mixed matrix membranes, with evidence of reduced physical aging, dependent on the particle type $[13,14]$. Supercritical $\mathrm{CO}_{2}\left(\mathrm{scCO}_{2}\right)$ is an alternative treatment approach, which is known to alter the permselectivity of membranes because of the ability of $\mathrm{scCO}_{2}$ to solvate the polymer chains. This results in faster polymeric chain rearrangement, as well as the possibility of transitioning the polymer to a rubbery state and; therefore, plasticizes the membrane. Hence, morphology changes can occur on a shorter time frame under $\mathrm{scCO}_{2}$ conditions. In addition, $\mathrm{scCO}_{2}$ has the potential to swell the polymeric structure upon depressurization [15]. Hence, $\mathrm{scCO}_{2}$ has the potential to beneficially alter the performance of PIMs-based membranes for gas separation.

In this investigation, polymer of intrinsic microporosity (PIM-1)-based membranes were exposed to $\mathrm{scCO}_{2}$ for two different exposure time periods and two different depressurization rates. The resulting membranes gas separation performances were investigated in terms of helium, nitrogen, methane, oxygen and carbon dioxide permeabilities. In addition, the physical aging of the PIM-1 membranes after exposure to $\mathrm{scCO}_{2}$ was also measured, with the results analysed to evaluate the potential of $\mathrm{scCO}_{2}$ to alter PIM-1 gas separation and aging properties.

\section{Materials and Methods}

PIM-1, the polycondensation product of ultrahigh purity monomers of 5,5',6,6'-tetrahydroxyl3,3,3' $3^{\prime}$-tetramethyl-1,1' ${ }^{\prime}$-spirobisindane (TTSBI) and 2,3,5,6-tetra fluoroterephthalonitrile (TFTPN), was synthesised following established procedures by Budd et al. [16]. Membranes of PIM-1 were cast from solutions of dichloromethane through controlled evaporation. The final film thickness was between 63 and $78 \mu \mathrm{m}$. All films were annealed at $150{ }^{\circ} \mathrm{C}$ for 1 day under vacuum to remove dichloromethane, and then cooled to room temperature overnight. The original membrane was washed with methanol and then allowed to dry to reverse any aging effects, while those membranes exposed to $\mathrm{scCO}_{2}$ were not $[9,17]$. Washing with methanol treatment of the $\mathrm{scCO}_{2}$ treated membranes reverts their morphology, similar to reversing aging effects.

Membrane densities were determined through standard procedures [18]. Gas sorption measurements of $\mathrm{CO}_{2}$ were undertaken on a gravimetric sorption analyser (GHP-FS, VTI Instruments) operating at $35{ }^{\circ} \mathrm{C}$. The pressure was incrementally adjusted from 0 to $20 \mathrm{~atm}$, with helium used for buoyancy correction [19]. Single gas permeabilities were undertaken on a variable pressure constant volume apparatus as previously described [20], with feed pressures of 8 atm and $35^{\circ} \mathrm{C}$. The permeability values were the average of three single gas measurements per gas with a fresh membrane each time; error margins corresponding to two standard deviations in the permeability data set. $\mathrm{ScCO}_{2}$ is achieved above $31.1^{\circ} \mathrm{C}$ and $72.9 \mathrm{~atm}$ [21]. The $\mathrm{scCO}_{2}$ treatment was undertaken in an autoclave equipped with the inlet of $\mathrm{CO}_{2}$ and a backpressure regulator; membranes were exposed at $246.7 \mathrm{~atm}$ and at $50^{\circ} \mathrm{C}$ for 2 or $8 \mathrm{~h}$. Depressurization back to ambient pressure was achieved through two mechanisms, rapid depressurization, which occurred over a few minutes (depressurization rate: $118 \mathrm{~atm} / \mathrm{min}$ ), and gradual depressurization, over $150 \mathrm{~min}$ (depressurization rate: $1.7 \mathrm{~atm} / \mathrm{min}$ ). 
Hence, the $\mathrm{scCO}_{2}$ treatment process was designed to investigate both the impact of exposure time and removal rate of $\mathrm{CO}_{2}$ on the underlying PIM-1 membrane's performance.

\section{Results and Discussion}

\section{1. $\mathrm{CO}_{2}$ Sorption Isotherm of PIM-1}

The sorption isotherm of $\mathrm{CO}_{2}$ in the original PIM-1 membrane is provided in Figure 1, as a function of pressure at $35{ }^{\circ} \mathrm{C}$. This isotherm was comparable to literature and followed standard dual-sorption model behaviour [22], with a significant sorption of $\mathrm{CO}_{2}$ at low pressures attributed to the micro-cavities within the membrane morphology being filled, while at higher pressures the micro-cavities became saturated and additional sorption was limited to the polymeric matrix. The $\mathrm{CO}_{2}$ concentration $(\mathrm{C})$ within the membrane can be modelled by dual-sorption theory [22]:

$$
\mathrm{C}=\mathrm{k}_{\mathrm{D}} \mathrm{p}+\frac{\mathrm{C}_{\mathrm{H}} \mathrm{bp}}{(1+\mathrm{bp})}
$$

where $\mathrm{p}$ is the pressure, $\mathrm{k}_{\mathrm{D}}$ the Henry's law constant, $\mathrm{C}_{\mathrm{H}}^{\prime}$ the maximum Langmuir adsorption capacity and $b$ the Langmuir affinity. The evaluated parameters are provided in Table 1.

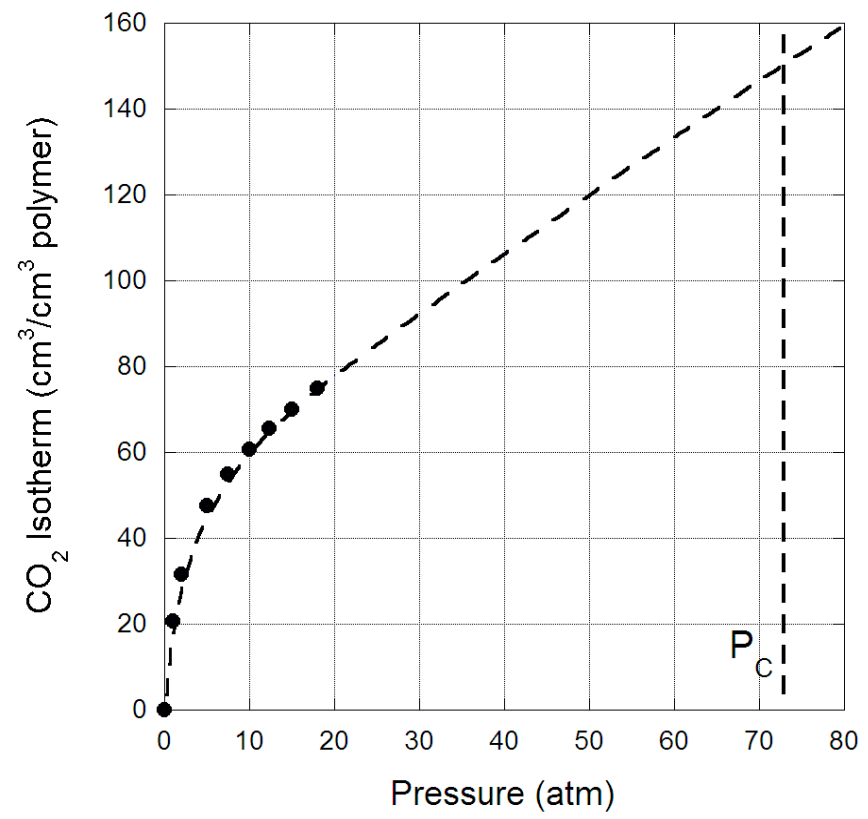

Figure 1. $\mathrm{CO}_{2}$ sorption isotherm $\left(\mathrm{cm}^{3} / \mathrm{cm}^{3}\right.$ polymer) in original polymer of intrinsic microporosity (PIM-1) membrane as a function of pressure, the isotherm is extrapolated out to the critical pressure of $\mathrm{CO}_{2}$.

Table 1. Dual-sorption parameters (Henry's law constant $\left(\mathrm{k}_{\mathrm{D}}\right)$, maximum Langmuir capacity $\left(\mathrm{C}^{\prime}{ }_{\mathrm{H}}\right)$ and Langmuir affinity (b) for $\mathrm{CO}_{2}$ in PIM-1 membrane at $35^{\circ} \mathrm{C}$.

\begin{tabular}{ccc}
\hline Parameter & This Work & Mason et al. [10] \\
\hline $\mathrm{k}_{\mathrm{D}}\left(\mathrm{cm}^{3} / \mathrm{cm}^{3} \mathrm{~atm}\right)$ & $1.3 \pm 0.1$ & 3.86 \\
$\mathrm{C}_{\mathrm{H}}^{\prime}\left(\mathrm{cm}^{3} / \mathrm{cm}^{3}\right)$ & $56 \pm 2$ & 52.8 \\
$\mathrm{~b}\left(\mathrm{~atm}^{-1}\right)$ & $0.52 \pm 0.03$ & 0.706 \\
\hline
\end{tabular}

These dual-sorption parameters were comparable to literature and reveal that the PIM-1 membrane studied here had similar morphology to those previous studies [10,23]. Interestingly, the $k_{D}$ and $b$ values for PIM-1 was significantly lower than other polymers investigated for $\mathrm{CO}_{2}$ 
separation, such as cellulose triacetate and polyimides [15]. This indicates that the PIM-1 polymer chain did not have strong affinity for $\mathrm{CO}_{2}$ relative to other polymers, and that the strong sorption was mainly attributed to the micro-cavities, which had a capacity significantly higher than other polymers.

The sorption analyser's maximum pressure was $20 \mathrm{~atm}$, and; therefore, determining the sorbed amount of $\mathrm{CO}_{2}$ up to the critical pressure could not be measured. However, the isotherm clearly followed standard dual-sorption mode behaviour, and hence it was possible to extrapolate the sorption behaviour to higher pressures to indicate how much $\mathrm{CO}_{2}$ could be sorbed into the membrane. This extrapolation is provided in Figure 1 only as a guide, since non-linear deviation in $\mathrm{CO}_{2}$ sorption is anticipated at significantly high pressures because of polymer plasticization and condensation of $\mathrm{scCO}_{2}$ in the membrane. Interestingly, the extrapolation suggests that PIM-1 membrane's sorption of $\mathrm{CO}_{2}$ at high pressures was not substantial, only a doubling of the amount of $\mathrm{CO}_{2}$ sorbed at $20 \mathrm{~atm}$. This is due to the relatively poor affinity the polymeric matrix has for $\mathrm{CO}_{2}$, compared to other polymers used for gas separation membranes [23]. Hence, the amount of $\mathrm{CO}_{2}$ sorbed at critical pressure would be comparable to cellulose triacetate [15], a midrange polymeric membrane with a permselectivity that is lower than the Robeson's upper bound, rather than other high performing polymers.

\subsection{Gas Permeability in Original PIM-1 Membrane}

The gas permeability through the original PIM-1 membrane is provided in Table 2 after seven days of aging, along with reported literature values. There was discrepancy between the reported gas permeabilities in the literature, as well as with those determined here, which is attributed to the casting history of the PIM-1 membrane. The earlier study of Budd et al. [24] had lower gas permeabilities compared to this work and that of Thomas et al. [25], because the earlier studies had different degrees of physical aging and had not undergone methanol restoration. The $\mathrm{CO}_{2}$ permeability reported here had a reasonable correlation with that of Thomas et al. [25], though all gases were higher, especially $\mathrm{CH}_{4}$ which was three times the magnitude. However, the $\mathrm{CH}_{4}$ result was similar to the membrane reported by Starannikova et al. [26], and there was also comparison in the $\mathrm{He}$ and $\mathrm{O}_{2}$ permeabilities of the two membranes. Hence, the wide variation in reported gas permeabilities for PIM-1 based membranes could be attributed to the differences in the morphology of the membrane, as a result of both the synthesising procedure and casting history.

Table 2. Gas permeability (barrer) in the original PIM-1 membrane at $35^{\circ} \mathrm{C}$, along with literature values.

\begin{tabular}{cccccc}
\hline & This Work & Budd et al. [24] & Staiger et al. [5] & Thomas et al. [25] & Starannikova et al. [26] \\
\hline $\mathrm{He}$ & $2055 \pm 90$ & 660 & 1061 & 1500 & 1740 \\
$\mathrm{~N}_{2}$ & $349 \pm 8$ & 92 & 238 & 340 & 830 \\
$\mathrm{O}_{2}$ & $1865 \pm 75$ & 370 & 786 & 1300 & 2390 \\
$\mathrm{CH}_{4}$ & $1307 \pm 26$ & 125 & 360 & 430 & 1440 \\
$\mathrm{CO}_{2}$ & $7595 \pm 84$ & 2300 & 3496 & 6500 & 15,300 \\
\hline
\end{tabular}

The selectivity of the original PIM-1 membrane is provided in Table 3, and displayed similar behaviour to literature, in that the membrane is clearly selective for $\mathrm{CO}_{2}$ against $\mathrm{CH}_{4}$ and $\mathrm{N}_{2}$; as well as being selective for $\mathrm{O}_{2}$ and He. However, the high $\mathrm{CH}_{4}$ permeability of this membrane resulted in the $\mathrm{CO}_{2} / \mathrm{CH}_{4}$ and $\mathrm{He} / \mathrm{CH}_{4}$ selectivity being lower than literature, and hence the membrane investigated here was not on the Robeson's upper bound for these gas pairs.

Table 3. Selectivity of PIM-1 membrane at $35^{\circ} \mathrm{C}$.

\begin{tabular}{cccccc}
\hline & This Work & Budd et al. [24] & Staiger et al. [5] & Thomas et al. [25] & Starannikova et al. [26] \\
\hline $\mathrm{CO}_{2} / \mathrm{CH}_{4}$ & $5.8 \pm 0.2$ & 18.4 & 9.7 & 15.1 & 10.6 \\
$\mathrm{CO}_{2} / \mathrm{N}_{2}$ & $21.8 \pm 0.7$ & 25.0 & 14.7 & 19.1 & 18.4 \\
$\mathrm{O}_{2} / \mathrm{N}_{2}$ & $5.3 \pm 0.3$ & 4.0 & 3.3 & 3.8 & 2.9 \\
$\mathrm{He} / \mathrm{N}_{2}$ & $5.9 \pm 0.4$ & 7.2 & 4.5 & 4.4 & 2.1 \\
$\mathrm{He} / \mathrm{CH}_{4}$ & $1.6 \pm 0.1$ & 5.3 & 2.9 & 3.5 & 1.2 \\
\hline
\end{tabular}




\subsection{Supercritical $\mathrm{CO}_{2}$ Treatment}

\subsubsection{Density}

The density of the original PIM-1 membrane and after treatment with $\mathrm{scCO}_{2}$ for two and eight hours, as well as rapid and slow depressurizations, is provided in Table 4, after seven days of aging. The density of the original membrane, after methanol regeneration, was $1.114 \mathrm{~g} / \mathrm{cm}^{3} . \mathrm{After} \mathrm{scCO}_{2}$ treatment, the density increased irrespective of the treatment protocol, and hence a denser morphology was obtained. This was associated with the ability of $\mathrm{scCO}_{2}$ to solubilise the polymer, enabling enhanced chain mobilization and rearrangement. As a consequence, the fractional free volume of $\mathrm{scCO}_{2}$-treated PIM-1 membrane would have reduced. Importantly, the longer eight-hour exposure resulted in a denser membrane morphology, than the shorter two-hour exposure, supporting the conclusion that polymer solubilisation was the dominate factor. The depressurization rate clearly impacted the morphology, with the rapid depressurization resulting in a lower density structure, irrespective of exposure time, which has been observed for other polymeric membranes exposed to $\mathrm{scCO}_{2}$ [15]. This dense morphology was clearly observed in SEM images for the rapid depressurization PIM-1 membranes, provided in Figure 2. The densities were greater than the original membrane, implying that the morphology changes due to rapid depressurization of the $\mathrm{scCO}_{2}$ were not great enough to reverse the polymer solubilisation effect. This density increase within the PIM-1 membranes differed from that observed for cellulose triacetate membranes exposed to $\mathrm{scCO}_{2}$, irrespective of depressurization, as well as polyimide-based membranes that underwent rapid depressurization, but was similar to polyimide membranes that experienced slow depressurization [15]. Hence, $\mathrm{scCO}_{2}$ treatment was polymer dependent.

Table 4. Density $\left(\mathrm{g} / \mathrm{cm}^{3}\right.$ ) and gas permeability (barrer) in supercritical $\mathrm{CO}_{2}$-treated PIM-1 membrane at $35^{\circ} \mathrm{C}$. The original untreated PIM-1 membrane had a density of $1.114 \mathrm{~g} / \mathrm{cm}^{3}$.

\begin{tabular}{ccccc}
\hline Exposure Time & \multicolumn{2}{c}{$\mathbf{2 ~ h}$} & \multicolumn{2}{c}{$\mathbf{h}$} \\
\hline Depressurization & Rapid & Slow & Rapid & Slow \\
\hline $\begin{array}{c}\text { Density }\left(\mathrm{g} / \mathrm{cm}^{3}\right) \\
\text { Permeability (barrer) }\end{array}$ & 1.142 & 1.215 & 1.184 & 1.306 \\
$\mathrm{He}$ & $1421 \pm 88$ & $1768 \pm 92$ & $1744 \pm 68$ & $1966 \pm 72$ \\
$\mathrm{~N}_{2}$ & $314 \pm 19$ & $338 \pm 12$ & $338 \pm 14$ & $338 \pm 16$ \\
$\mathrm{O}_{2}$ & $1245 \pm 64$ & $1577 \pm 69$ & $1444 \pm 63$ & $1513 \pm 72$ \\
$\mathrm{CH}_{4}$ & $823 \pm 21$ & $887 \pm 24$ & $788 \pm 16$ & $857 \pm 22$ \\
$\mathrm{CO}_{2}$ & $5118 \pm 157$ & $7068 \pm 83$ & $6621 \pm 164$ & $6989 \pm 96$ \\
\hline
\end{tabular}
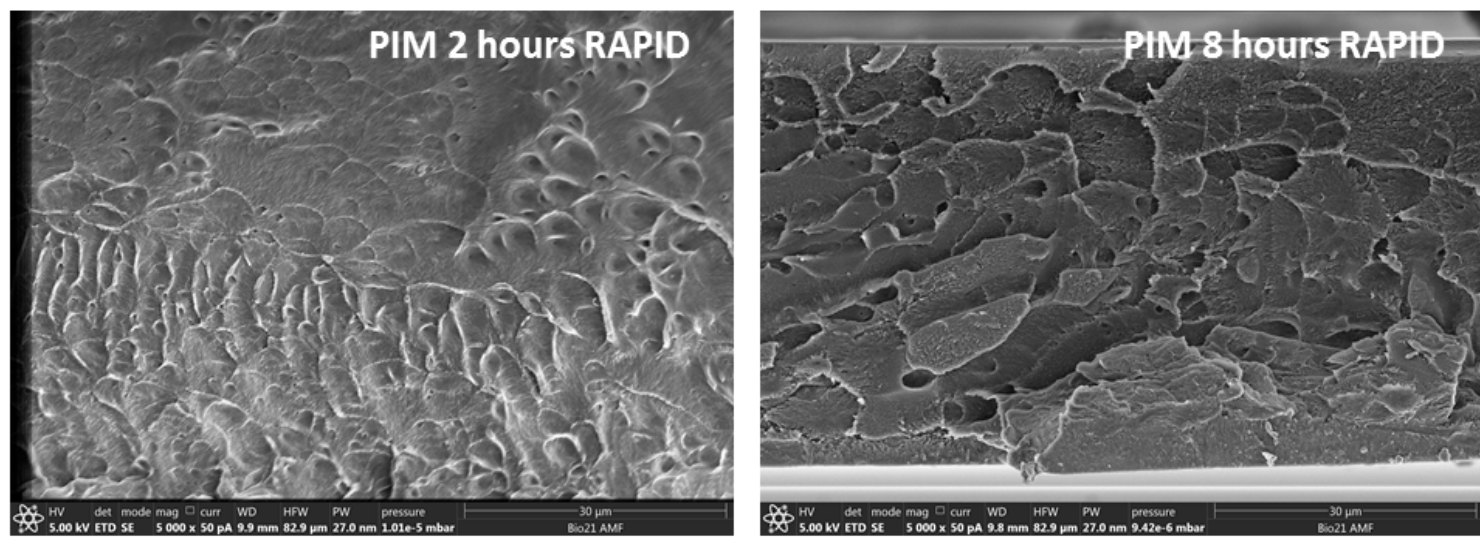

Figure 2. Scanning electron microscope (SEM) images of the PIM-1 membranes after two- and eight-h exposure to $\mathrm{scC}_{2}$, with rapid depressurization. 


\subsubsection{Gas Permeability}

The gas permeability through the PIM-1 membrane after treatment with $\mathrm{scCO}_{2}$ is provided in Table 4, after seven days of aging, for two and eight-hour exposure, as well as rapid and slow depressurization. All four $\mathrm{scCO}_{2}$ treatments resulted in a reduction in the gas permeability through the membrane, compared to the original membrane (Table 2). This behaviour corresponded well with the increased density of the $\mathrm{scCO}_{2}$ treated membranes, implying that the PIM-1 morphology change restricts gas permeance. The exception was $\mathrm{N}_{2}$, which was essentially unchanged, within error, of the original membrane result. The low permeability of $\mathrm{N}_{2}$ in the original and $\mathrm{scCO}_{2}$ treated membranes implies that the PIM-1 membrane morphology remained unfavourable for $\mathrm{N}_{2}$, and the interaction with $\mathrm{scCO}_{2}$ did not alter this.

There was a clear trend in the $\mathrm{scCO}_{2}$ treatment protocol on the membrane, with rapid depressurization having reduced gas permeabilities compared to slow depressurization, for the same exposure time. This reveals that rapidly removing the $\mathrm{scCO}_{2}$ from the PIM- 1 membrane alters the morphology to be less favourable for gas permeance compared to slow depressurization. This was counter to the observation for other polymeric membranes exposed to $\mathrm{scCO}_{2}$, notably cellulose triacetate and polyimide [15], where rapid depressurization resulted in swelling. This behaviour was also counter to the density measurements (Table 4), where a lower density usually corresponded to increased gas permeability. This difference was attributed to the higher fractional free volume of PIM-1 and the already high permeance of $\mathrm{CO}_{2}$ enabling the $\mathrm{scCO}_{2}$ to rapidly desorb through the established connecting pathways between micro-cavities. This limited the ability of $\mathrm{scCO}_{2}$ to generate new pathways for desorption during rapid depressurization and, hence, the PIM-1 structure did not swell, as the resulting densities of the rapid depressurization membranes remained greater than the original membrane. Why the slower depressurization protocol resulted in higher gas permeabilities is unknown, given the denser morphology (Table 4); but the behaviour does suggest that the existing and established pathways through PIM-1 membranes' micro-cavities remained open during $\mathrm{scCO}_{2}$ treatment, most likely because of the strong accumulation of $\mathrm{scCO}_{2}$ in these free volume regions. The variability in gas permeability after $\mathrm{scCO}_{2}$ treatment of various polymeric membranes [15] further establishes that the change in morphology and gas separation properties outcomes are polymer dependent.

The corresponding selectivity of the PIM- 1 membranes after $\mathrm{scCO}_{2}$ treatment are provided in Table 5. Compared to the original membrane there was clear deviation for the $\mathrm{scCO}_{2}$ membranes. For separation from $\mathrm{CH}_{4}$ (i.e., $\mathrm{CO}_{2} / \mathrm{CH}_{4}$ and $\mathrm{He} / \mathrm{CH}_{4}$ ) the $\mathrm{scCO}_{2}$-treated membranes showed an increase in selectivity over the original membrane. This was a direct result of the $\mathrm{CH}_{4}$ permeability reducing by $32 \%-39 \%$ after exposure to $\mathrm{scCO}_{2}$, while the $\mathrm{CO}_{2}$ permeability was reduced by only $7 \%-32 \%$ and $\mathrm{He}$ permeability reduced by $4 \%-31 \%$. In contrast, $\mathrm{CO}_{2} / \mathrm{N}_{2}$ and $\mathrm{He} / \mathrm{N}_{2}$ selectivity decreased after exposure to $\mathrm{scCO}_{2}$, which was a direct result of the $\mathrm{N}_{2}$ permeability, through the $\mathrm{scCO}_{2}$-treated PIM-1 membranes, remaining essentially constant with the original membrane. Furthermore, there was evidence that longer $\mathrm{scCO}_{2}$ exposure time and slower depressurization result in higher selectivity than rapid depressurization.

Table 5. Selectivity of supercritical $\mathrm{CO}_{2}$-treated PIM-1 membrane at $35^{\circ} \mathrm{C}$.

\begin{tabular}{ccccc}
\hline Exposure Time & \multicolumn{2}{c}{$\mathbf{2 ~ h}$} & \multicolumn{2}{c}{$\mathbf{8 h}$} \\
\hline Depressurization & Rapid & Slow & Rapid & Slow \\
\hline $\mathrm{CO}_{2} / \mathrm{CH}_{4}$ & $6.2 \pm 0.3$ & $8.0 \pm 0.3$ & $8.4 \pm 0.4$ & $8.2 \pm 0.3$ \\
$\mathrm{CO}_{2} / \mathrm{N}_{2}$ & $16.3 \pm 1.5$ & $20.9 \pm 1.0$ & $19.6 \pm 1.3$ & $20.7 \pm 1.3$ \\
$\mathrm{O}_{2} / \mathrm{N}_{2}$ & $4.0 \pm 0.4$ & $4.7 \pm 0.4$ & $4.3 \pm 0.4$ & $4.5 \pm 0.4$ \\
$\mathrm{He} / \mathrm{N}_{2}$ & $4.5 \pm 0.6$ & $5.2 \pm 0.5$ & $5.2 \pm 0.4$ & $5.8 \pm 0.5$ \\
$\mathrm{He} / \mathrm{CH}_{4}$ & $1.7 \pm 0.1$ & $2.0 \pm 0.2$ & $2.2 \pm 0.1$ & $2.3 \pm 0.1$ \\
\hline
\end{tabular}




\subsubsection{Aging Study}

The change in He permeability through PIM-1 membranes over an extended period of time is provided in Figure 3, for both the original membrane and the four $\mathrm{scCO}_{2}$-treated protocols. For all five membranes the He permeability decreased with time, indicative of physical aging. There were differences between the permeabilities presented in Figures 3-7, and those presented in Table 4, as they represent different PIM-1 membranes that were measured at different times after $\mathrm{scCO}_{2}$ treatment. Over the 63 days studied, all five membranes experienced similar aging behaviour, losing 200 barrer in He permeability at the 63-day mark. Interestingly, there was no difference between the original and $\mathrm{scCO}_{2}$-treated membranes in terms of He aging. This suggests $\mathrm{scCO}_{2}$ exposure had not changed the mechanism of physical aging; that of lattice contraction within the PIM-1 structure [8], as polymer chains rearrange to a denser state. A comparable increase in density of the PIM-1 membranes was observed in the aging period, with the two hours slow depressurization PIM-1 membrane experiencing a density increase of 5\%. However, He was not a good indicator of micro-cavity change, because being the smallest molecule enabled He to permeate more readily through the micro-cavities and polymeric matrix compared to other gases.

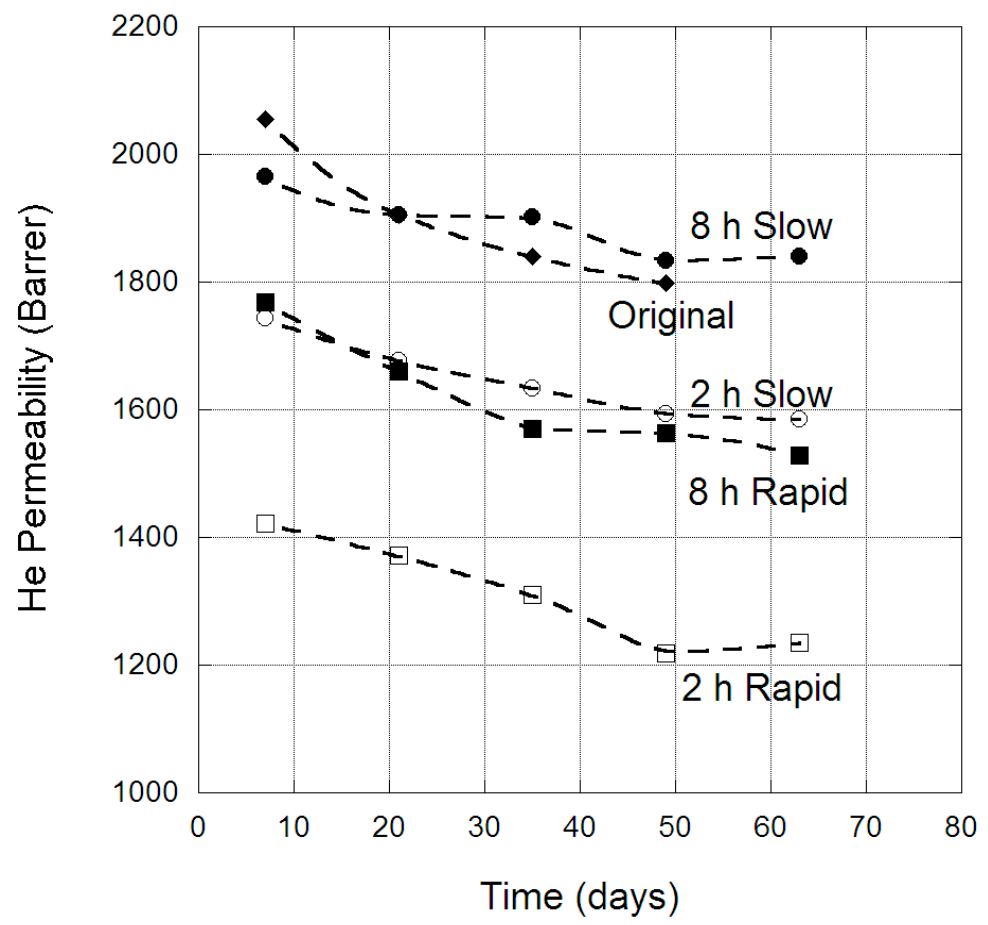

Figure 3. He permeability (barrer) in PIM-1 membranes over time, for the original and $\mathrm{scCO}_{2}$-treated states, at $35^{\circ} \mathrm{C}$.

The change in $\mathrm{CO}_{2}$ permeability through PIM-1 membranes over an extended period of time is provided in Figure 4, for both the original membrane and the four $\mathrm{scCO}_{2}$-treated protocols. Again, there was clear evidence of physical aging, with an initial pronounced loss in permeability over the first two weeks, which progressed to a gradual reduction over the longer time period. The effect of physical aging on $\mathrm{He}$ and $\mathrm{CO}_{2}$ permeabilities was clearly different, which is attributed to the relative sizes of the gases. $\mathrm{CO}_{2}$ is significantly large that its permeance through the PIM-1 morphology is dominated by transport through the micro-cavities, which becomes restricted as the membrane ages. The original membrane $\mathrm{CO}_{2}$ permeability was reduced by $\sim 2500$ barrer over the 49 days studied, while the $\mathrm{scCO}_{2}$-treated membranes experienced a larger reduction of 2500 to 3500 barrer over the aging period. Hence, the $\mathrm{scCO}_{2}$ treated process had enhanced the physical aging impact on $\mathrm{CO}_{2}$ permeability. This is attributed to the denser membrane structure (Table 4), resulting from $\mathrm{scCO}_{2}$ treatment having reduced the micro-cavities in which $\mathrm{CO}_{2}$ transverses through the PIM-1 membrane, and hence physical 
aging in the remaining micro-cavities was more pronounced on $\mathrm{CO}_{2}$ permeability, which appeared as an enhancement of physical aging.

The change in $\mathrm{CH}_{4}$ permeability through PIM-1 membranes over time is provided in Figure 5, for both the original membrane and the four $\mathrm{scCO}_{2}$-treated protocols. For $\mathrm{CH}_{4}$, there was a clear difference in the physical aging behaviour of the original membrane and those treated with $\mathrm{scCO}_{2}$. The original membrane $\mathrm{CH}_{4}$ permeability was reduced by $\sim 500$ barrer over 50 days, while membranes exposed to $\mathrm{scCO}_{2}$ for two hours experienced a physical aging loss of $\sim 300$ barrer, and membranes treated for eight hours experienced less than 200 barrer loss in $\mathrm{CH}_{4}$ permeability over 63 days. Similar behaviour was also clearly observed for $\mathrm{N}_{2}$ and $\mathrm{O}_{2}$ permeability in PIM-1 membranes over time, as provided in Figures 6 and 7, respectively. Hence, exposure to eight hours of $\mathrm{scCO}_{2}$ resulted in a morphology that underwent minor physical aging in terms of $\mathrm{CH}_{4}, \mathrm{~N}_{2}$ and $\mathrm{O}_{2}$ permeability, while two hours $\mathrm{scCO}_{2}$ exposure gave rise to physical aging that was significantly reduced compared to the original membrane for the same gases. This was attributed to the $\mathrm{scCO}_{2}$ treatment reducing the larger micro-cavities, by creating a denser morphology, in which $\mathrm{CH}_{4}, \mathrm{~N}_{2}$ and $\mathrm{O}_{2}$ would previously permeate through PIM-1 (as evident by the decrease in permeability of $\mathrm{CH}_{4}$ and $\mathrm{O}_{2}$ between the original and $\mathrm{scCO}_{2}$ treated membranes). Hence, further micro-cavity contraction due to physical aging had only a minor impact on $\mathrm{CH}_{4}, \mathrm{~N}_{2}$ and $\mathrm{O}_{2}$, as they were already size excluded from the micro-cavities in which $\mathrm{CO}_{2}$ and He permeate. This became notable in the change in selectivity of the membrane over time, with the $\mathrm{CO}_{2} / \mathrm{N}_{2}$ selectivity of the eight-hour exposed membrane (irrespective of depressurization protocol) decreasing to 10.3 over the 63 days. Similar, changes were also observed in the $\mathrm{CO}_{2} / \mathrm{CH}_{4}$ selectivity, which decreased to 4.6 over the 63 days; highlighting the magnitude of the decrease in $\mathrm{CO}_{2}$ permeability relative to the larger gases.

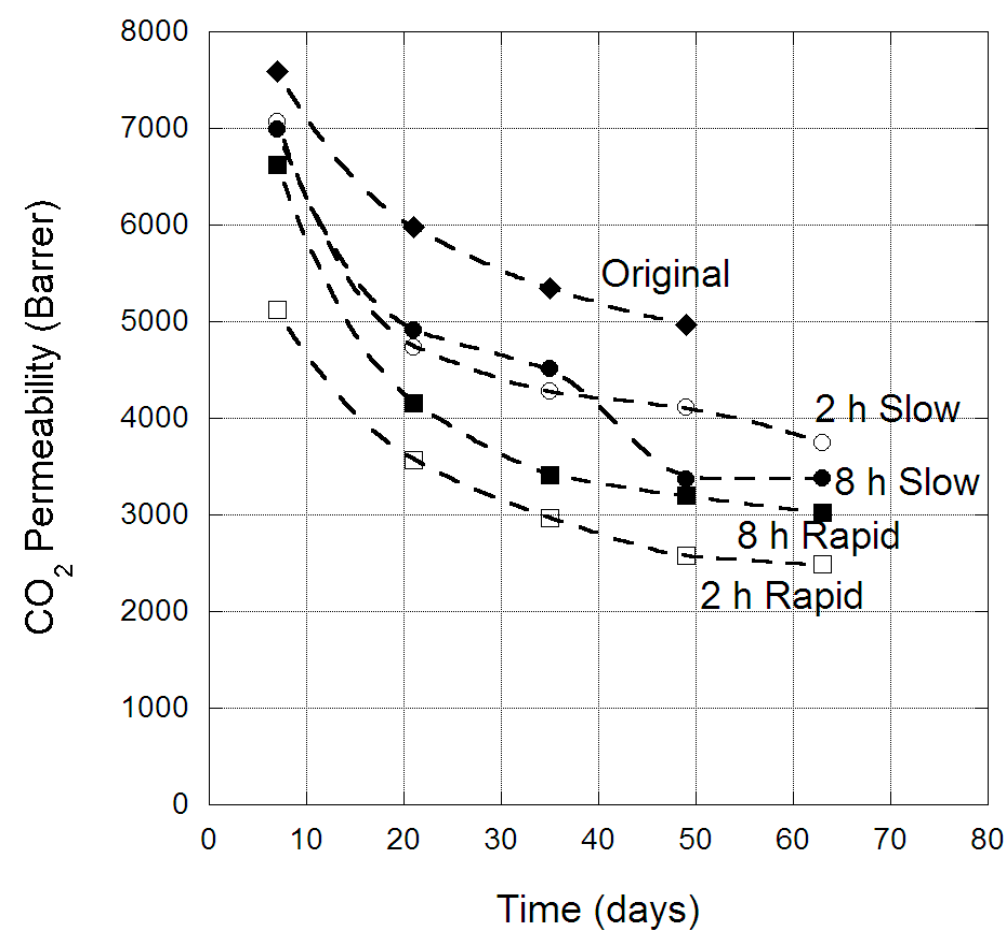

Figure 4. $\mathrm{CO}_{2}$ permeability (barrer) in PIM-1 membrane over time, for the original and $\mathrm{scCO}_{2}$-treated states, at $35^{\circ} \mathrm{C}$. 


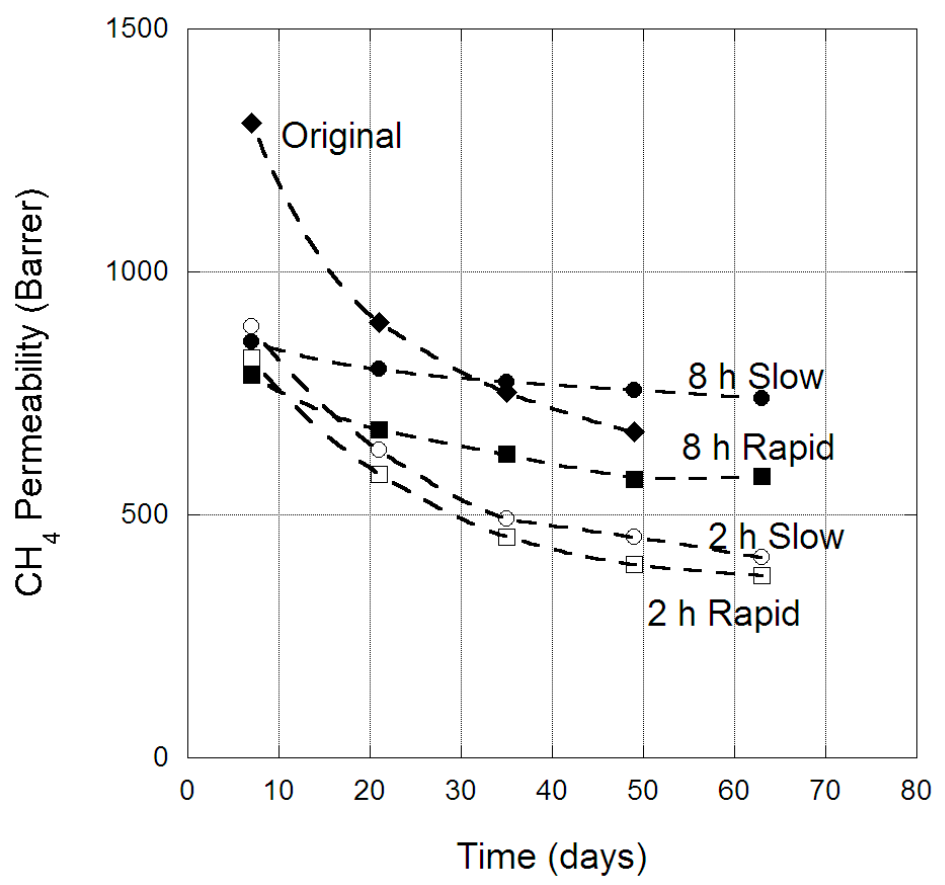

Figure 5. $\mathrm{CH}_{4}$ permeability (barrer) in PIM-1 membrane over time, for the original and $\mathrm{scCO}_{2}$-treated states, at $35{ }^{\circ} \mathrm{C}$.

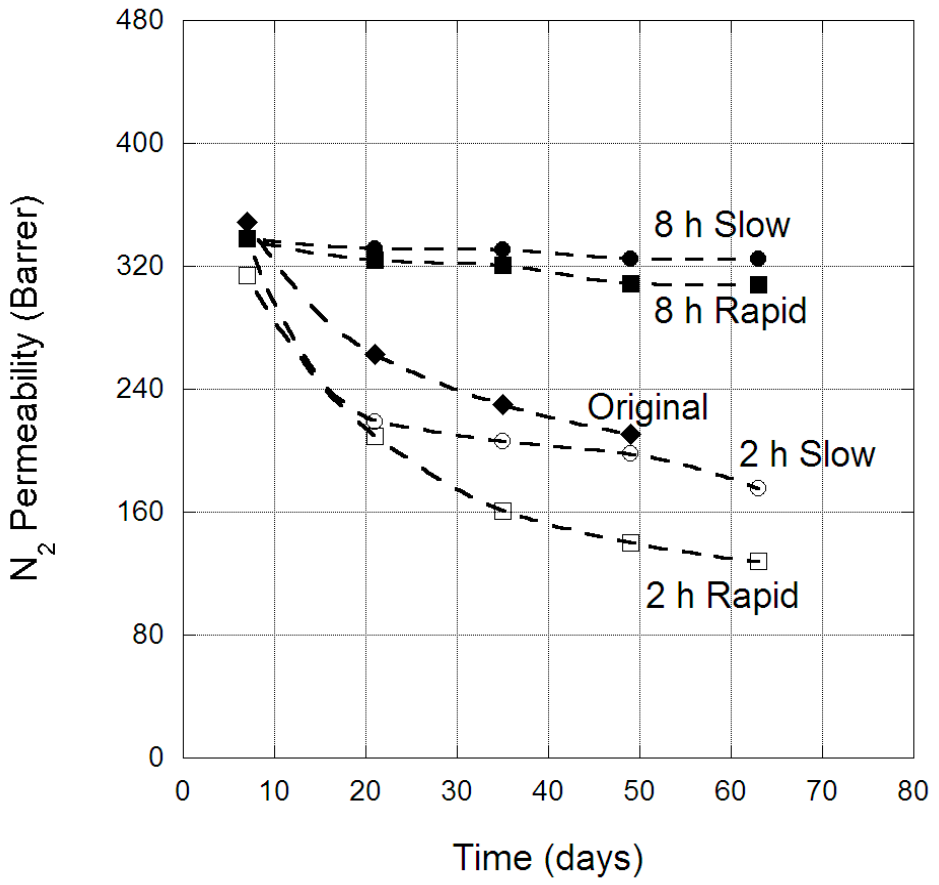

Figure 6. $\mathrm{N}_{2}$ permeability (barrer) in PIM-1 membrane over time, for the original and $\mathrm{scCO}_{2}$-treated states, at $35^{\circ} \mathrm{C}$.

The physical aging of gas permeability in PIM-1 membranes can be described by a power law, as established by Bernardo et al. [27]:

$$
\mathrm{P}=\mathrm{P}_{0} \mathrm{t}^{-\beta_{\mathrm{P}}}
$$

where $P_{0}$ is the initial permeability of the membrane at $t=1$ and $\beta_{P}$ the permeability aging rate constant. The determined $\beta_{\mathrm{P}}$ values for the original and $\mathrm{scCO}_{2}$-treated PIM-1 membranes are provided in Figure 8, as a function of the squared effective diameter of the gases studied, $\mathrm{CO}_{2}$ is at $0.091 \mathrm{~nm}^{2}$ 
and $\mathrm{N}_{2}$ is at $0.092 \mathrm{~nm}^{2}$. The original PIM- 1 membrane had very similar $\beta_{P}$ values to that reported by Bernardo et al. [27], and hence comparable physical aging with that study, which included an ethanol treatment post-fabrication. For the $\mathrm{scCO}_{2}$-treated PIM-1 there was a clear reduction in the aging constant for those membranes exposed for eight hours, along with a loss in correlation associated with gas diameter. The explanation to this behaviour is attributed to $\mathrm{CO}_{2}$ solubilising the polymer chain and creating a denser morphology the longer PIM-1 is exposed; however, $\mathrm{scCO}_{2}$ when desorbing leaves behind micro-cavities of sufficient size to enable depressurization. These micro-cavities then undergo physical aging, which was observed in the permeability loss of $\mathrm{He}$ and $\mathrm{CO}_{2}$; while $\mathrm{CH}_{4}, \mathrm{~N}_{2}$ and $\mathrm{O}_{2}$ are larger molecules and thus size restricted from these post $\mathrm{scCO}_{2}$ micro-cavities, and hence do not experience physical aging to the same degree as their permeabilities are already reduced.

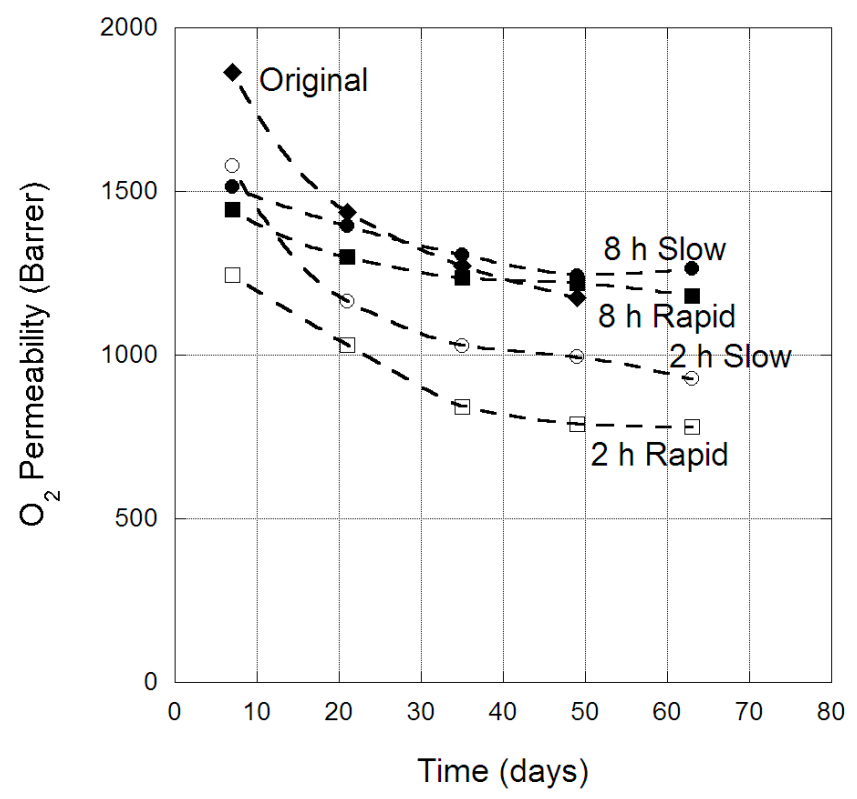

Figure 7. $\mathrm{O}_{2}$ permeability (barrer) in PIM-1 membrane over time, for the original and $\mathrm{scCO}_{2}$-treated states, at $35^{\circ} \mathrm{C}$.

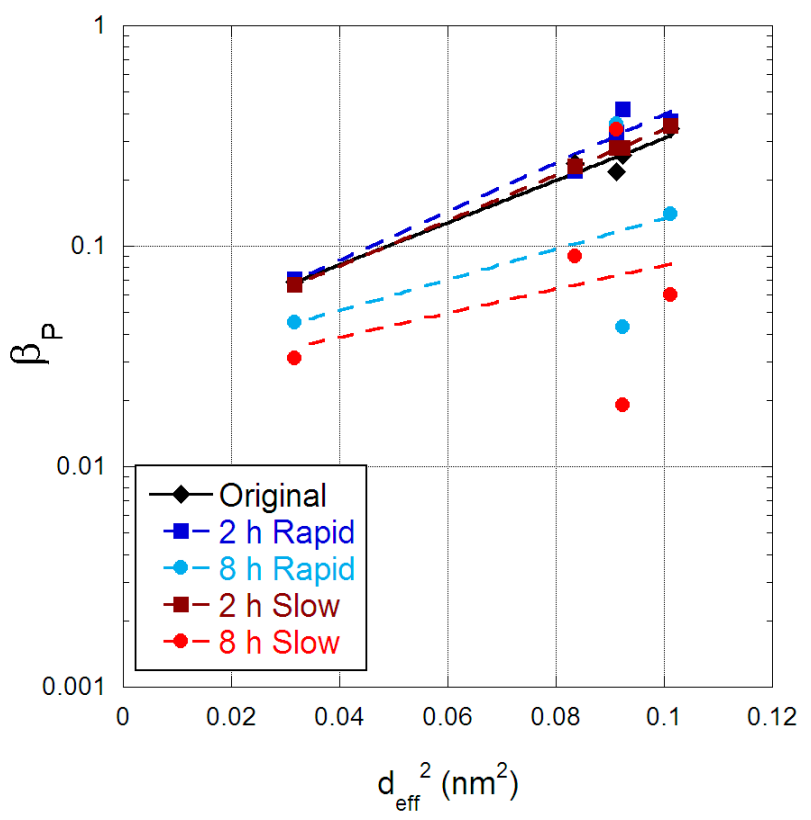

Figure 8. Aging rate constant for PIM-1 membranes as a function of the square of the effective gas diameter $\left(\mathrm{nm}^{2}\right)$. 


\section{Conclusions}

The permeability and selectivity of PIM-1 membranes for gas separation are impacted by exposure to $\mathrm{scCO}_{2}$, due to the process creating a denser membrane morphology. $\mathrm{He}, \mathrm{CH}_{4}, \mathrm{O}_{2}$ and $\mathrm{CO}_{2}$ all experience a reduction in permeability through the membrane, while $\mathrm{N}_{2}$ permeability remains relatively constant, when PIM-1 is exposed to $\mathrm{scCO}_{2}$ for two or eight hours, at the end of which the process undergoes rapid or slow depressurization. This is attributed to $\mathrm{scCO}_{2}$ solubilising the PIM-1 polymer chain, enabling polymer chain rearrangement and altering the micro-cavity environment. Interestingly, the physical aging of PIM-1 membranes is altered by exposure to $\mathrm{scCO}_{2}$. He and $\mathrm{CO}_{2}$ permeabilities are observed to decrease significantly over extend time periods due to contraction of the micro-cavities within PIM-1; however, $\mathrm{N}_{2}, \mathrm{CH}_{4}$ and $\mathrm{O}_{2}$ permeabilities experience only a small reduction over the same time period, especially if the PIM- 1 membrane had been exposed to $\mathrm{scCO}_{2}$ for eight hours. This is attributed to the initial $\mathrm{scCO}_{2}$ exposure contracting the larger micro-cavities, reducing $\mathrm{N}_{2}, \mathrm{CH}_{4}$ and $\mathrm{O}_{2}$ permeabilities because of size exclusion, as such subsequent aging in those micro-cavities does not impact those gases permeabilities because they are already excluded. Hence, $\mathrm{scCO}_{2}$ exposure is a procedure that has potential implications in reducing the impact of physical aging in PIM-1-based membranes for $\mathrm{N}_{2}, \mathrm{CH}_{4}$ and $\mathrm{O}_{2}$ separation.

Author Contributions: Conceptualization, C.A.S. and S.K.; methodology, C.A.S. and S.K.; formal analysis, C.A.S.; investigation, C.A.S.; data curation, C.A.S.; writing-original draft preparation, C.A.S.; writing-review and editing, S.K.; visualization, C.A.S.; and project administration, C.A.S.

Funding: This research received no external funding.

Acknowledgments: The authors would like to thank Jianyong Jin at the University of Auckland for supplying some of the PIM-1 base polymer used in this research.

Conflicts of Interest: The authors declare no conflicts of interest.

\section{References}

1. McKeown, N.B.; Budd, P.M. Polymers of intrinsic microporosity (PIMs): Organic materials for membrane separation, hetergeneous catalysis and hydrogen storage. Chem. Soc. Rev. 2006, 35, 675-683. [CrossRef]

2. Li, P.; Chung, T.S.; Paul, D.R. Gas sorption and permeation in PIM-1. J. Membr. Sci. 2013, 432, 50-57. [CrossRef]

3. Robeson, L.M. The upper bound revisited. J. Membr. Sci. 2008, 320, 390-400. [CrossRef]

4. Pilnacek, K.; Vopicka, O.; Lanc, M.; Dendisova, M.; Zgazar, M.; Budd, P.M.; Carta, M.; Malpass-Evans, R.; McKeown, N.B.; Friess, K. Aging of polymers of intrinsic microporosity tracked by methanol vapour permeation. J. Membr. Sci. 2016, 520, 895-906. [CrossRef]

5. Staiger, C.L.; Pas, S.J.; Hill, A.J.; Cornelius, C.J. Gas separation, free volume distribution, and physical aging of a highly microporous spirobisindane polymer. Chem. Mater. 2008, 20, 2606-2608. [CrossRef]

6. Baschetti, M.G.; Ghisellini, M.; Quinzi, M.; Doghieri, F.; Stagnaro, P.; Costa, G.; Sarti, G.C. Effects on sorption and diffusion in PTMSP and TMSP/TMSE copolymers of free volume changes due to polymer aging. J. Mol. Struct. 2005, 739, 75-86. [CrossRef]

7. Masuda, T.; Isobe, E.; Higashimura, T.; Takada, K. Poly[1-(trimethylsilyl)-1-propyne]: A new high polymer synthesized with transition-metal catalysts and characterized by extremely high gas permeability. J. Am. Chem. Soc. 1983, 105, 7473-7474. [CrossRef]

8. Swaidan, R.; Ghanem, B.; Litwiller, E.; Pinnau, I. Physical aging, plasticization and their effects on gas permeation in "rigid" polymers of intrinsic microporosity. Macromolecules 2015, 48, 6553-6561. [CrossRef]

9. Budd, P.M.; McKeown, N.B.; Ghanem, B.S.; Msayib, K.J.; Fritsch, D.; Starannikova, L.; Belov, N.; Sanfirova, O.; Yampolskii, Y.; Shantarovich, V. Gas permeation parameters and other physicochemical properties of a polymer of intrinsic microporosity: Polybenzodioxane PIM-1. J. Membr. Sci. 2008, 325, 851-860. [CrossRef]

10. Mason, C.R.; Maynard-Atem, L.; Heard, K.W.J.; Satilmis, B.; Budd, P.M.; Friess, K.; Lanc, M.; Bernardo, P.; Clarizia, G.; Jansen, J.C. Enhancement of $\mathrm{CO}_{2}$ affinity in a polymer of intrinsic microporosity by amine modification. Macromolecules 2014, 47, 1021-1029. [CrossRef] 
11. Li, F.Y.; Chung, T.S. Physical aging, high temperature and water vapor permeation studies of UV-rearranged PIM-1 membranes for advanced hydrogen purification and production. Int. J. Hydrog. Energy 2013, 38, 9786-9793. [CrossRef]

12. Du, N.; Cin, M.M.D.; Pinnau, I.; Nicalek, A.; Robertson, G.P.; Guiver, M.D. Azide-based cross-linking of polymers of intrinsic microporosity (PIMs) for condensable gas seapration. Macromol. Rapid Commun. 2011, 32, 631-636. [CrossRef]

13. Bushell, A.F.; Attfield, M.P.; Mason, C.R.; Budd, P.M.; Yampolskii, Y.; Starannikova, L.; Robrov, A.; Bazzarelli, F.; Bernardo, P.; Jansen, J.C.; et al. Gas permeation parameters of mixed matrix membranes based on the polymer of intrinsic microporosity PIM-1 and the zeolitic imidazolate framework ZIF-8. J. Membr. Sci. 2013, 427, 48-62. [CrossRef]

14. Du, N.; Park, H.B.; Robertson, G.P.; Dal-Cin, M.M.; Visser, T.; Scoles, L.; Guiver, M.D. Polymer nanosieve membranes for $\mathrm{CO}_{2}$-capture application. Nat. Mater. 2011, 10, 372-375. [CrossRef] [PubMed]

15. Scholes, C.A.; Kanehashi, S. Polymeric membrane gas separation performance improvements thorugh supercritical $\mathrm{CO}_{2}$ treatment. J. Membr. Sci. 2018, 566, 239-248. [CrossRef]

16. Budd, P.M.; Ghanem, B.S.; Makhseed, S.; McKeown, N.B.; Msayib, K.J.; Tattershall, C.E. Polymers of intrinsic microporosity (PIMs): Robust, solution-processable, organic nanoporous materials. Chem. Commun. 2004, 10, $230-231$. [CrossRef]

17. Hill, A.J.; Pas, S.J.; Bastow, T.J.; Burgar, M.I.; Nagai, K.; Toy, L.G.; Freeman, B.D. Influence of methanol conditioning and physical aging on carbon spin-lattice relaxation times of poly(1-trimethylsilyl-1-propyne). J. Membr. Sci. 2004, 243, 37-44. [CrossRef]

18. ASTM. Standard Test Methods for Density and Specific Gravity (Relative Density) of Plasticis by Displacement; ASTM International: West Conshohocken, PA, USA, 1993.

19. Scholes, C.A.; Tao, W.X.; Stevens, G.W.; Kentish, S.E. Sorption of methane, nitrogen, carbon dioxide, and water in Matrimid 5218. Appl. Polym. Sci. 2010, 117, 2284-2289. [CrossRef]

20. Duthie, X.; Kentish, S.E.; Powell, C.; Nagai, K.; Qiao, G.; Stevens, G.W. Operating temperature effects on the plasticization of polyimide gas separation membranes. J. Membr. Sci. 2007, 294, 40-49. [CrossRef]

21. Poling, B.E.; Prausnitz, J.M.; O'Connell, J.P. The Properties of Gaes and Liquids; McGraw Hill: New York, NY, USA, 2001.

22. Petropoulos, J.H. Mechanisms and theories for sorption and diffusion of gases in polymers. In Polymeric Gas Separation; Paul, D.R., Yampolskii, Y., Eds.; CRC Press: Boca Raton, FL, USA, 1994; pp. 17-81.

23. Scholes, C.A.; Jin, J.; Stevens, G.W.; Kentish, S.E. Competitive permeation of gas and water vapour in high free volume polymeric membranes. J. Polym. Sci. B Polym. Phys. 2015, 53, 719-728. [CrossRef]

24. Budd, P.M.; Msayib, K.J.; Tattershall, C.E.; Ghanem, B.S.; Reynolds, K.J.; McKeown, N.B.; Fritsch, D. Gas separation membranes from polymers of intrinsic microporosity. J. Membr. Sci. 2005, 251, 263-269. [CrossRef]

25. Thomas, S.; Pinnau, I.; Du, N.; Guiver, M.D. Pure- and mixed-gas permeation properties of a microporous spirobisindane-based ladder polymer (PIM-1). J. Membr. Sci. 2009, 333, 125-131. [CrossRef]

26. Starannikova, L.; Belov, N.; Shantarovich, V.; Zhang, J.; Jin, J.; Yampolskii, Y. Effective increase in permeability and free volume of PIM copolymers containing ethanoanthracene unit and comparison between the alternating and random copolymers. J. Membr. Sci. 2018, 548, 593-597. [CrossRef]

27. Bernardo, P.; Bazzarelli, F.; Tasselli, F.; Clarizia, G.; Mason, C.R.; Maynard-Atem, L.; Budd, P.M.; Lanc, M.; Pilnacek, K.; Vopicka, O.; et al. Effect of physical aging on the gas transport and sorption in PIM-1 membranes. Polymer 2017, 113, 283-294. [CrossRef]

(C) 2019 by the authors. Licensee MDPI, Basel, Switzerland. This article is an open access article distributed under the terms and conditions of the Creative Commons Attribution (CC BY) license (http://creativecommons.org/licenses/by/4.0/). 